\title{
Correction to: Leukemia Inhibitory Factor Increases Survival of Pluripotent Stem Cell-Derived Cardiomyocytes
}

\author{
Carolina Blüguermann $^{1}$ - Leonardo Romorini ${ }^{1,2}$ • Denis Evseenko ${ }^{3} \cdot$ Ximena Garate $^{1}$ • \\ Gabriel Neiman $^{1}$ • Gustavo Emilio Sevlever ${ }^{1}$ - María Elida Scassa ${ }^{1}$ • \\ Santiago Gabriel Miriuka ${ }^{1,2}$ (B)
}

Published online: 14 November 2017

(C) Springer Science+Business Media, LLC, part of Springer Nature 2017

Correction to: J. of Cardiovasc. Trans. Res

https://doi.org/10.1007/s12265-017-9769-6

Please note that Carolina Blüguermann's surname was misspelled (as Blugüermann) in this article as originally published.

The online version of the original article can be found at https://doi.org/ 10.1007/s12265-017-9769-6

\section{Santiago Gabriel Miriuka}

smiriuka@fleni.org.ar

1 LIAN-CONICETBelén de EscobarArgentina, Buenos Aires, Argentina

2 Consejo Nacional de Investigaciones Científicas y Técnicas (CONICET) Ciudad Autónoma de Buenos Aires, Buenos Aires, Argentina

3 Hoffman Medical Research CenterUniverstiy of Southern California, Los Angeles, CA, USA 